University of Arkansas, Fayetteville

ScholarWorks@UARK

$5-2016$

\title{
Calcium and magnesium absorption and retention by growing goats offered diets with different calcium sources.
}

Jennifer Long

University of Arkansas, Fayetteville

Follow this and additional works at: https://scholarworks.uark.edu/anscuht

Part of the Agriculture Commons, and the Sheep and Goat Science Commons

\section{Citation}

Long, J. (2016). Calcium and magnesium absorption and retention by growing goats offered diets with different calcium sources.. Animal Science Undergraduate Honors Theses Retrieved from https://scholarworks.uark.edu/anscuht/10

This Thesis is brought to you for free and open access by the Animal Science at ScholarWorks@UARK. It has been accepted for inclusion in Animal Science Undergraduate Honors Theses by an authorized administrator of ScholarWorks@UARK. For more information, please contact scholar@uark.edu. 


\section{Calcium and magnesium absorption and retention by growing goats offered diets with different calcium sources.}

Jennifer E. Long

University of Arkansas Division of Agriculture, Fayetteville, AR 


\section{Table of Contents}

Literature Review 3

$\begin{array}{lr}\text { Literature Review Literature Cited } & 8\end{array}$

$\begin{array}{lr}\text { Abstract } & 12\end{array}$

$\begin{array}{ll}\text { Introduction } & 13\end{array}$

$\begin{array}{ll}\text { Methods and Materials } & 13\end{array}$

$\begin{array}{ll}\text { Results and Discussion } & 15\end{array}$

$\begin{array}{ll}\text { Summary and Conclusion } & 18\end{array}$

$\begin{array}{lr}\text { Literature Cited } & 19\end{array}$

$\begin{array}{ll}\text { Tables } & 21\end{array}$ 


\section{Calcium Use in the Body}

Calcium is one of the most abundant elements in the body and is often the major cation in the diet. Calcium is essential for growth and maintenance of bones and teeth and is the most abundant mineral in the body. Ninety-nine percent of the body's calcium is located in the skeleton and the remaining $1 \%$ is extremely important in cellular metabolism, blood clotting, enzyme activation, and neuromuscular action (Soares et al., 1995). Calcium is critical in the structural component of the skeleton. Calcium deficiency in young animals leads to delayed growth and development, which can predispose them to rickets and in adults a calcium deficiency can lead to the disease osteomalacia (Pond et al. 2005).

Blood is the transport medium by which calcium is moved from the GI tract to other tissues for utilization (Pond et al,. 2005). Dietary factors that affect calcium absorption have an effect on the endocrine system in direct response to the amount of calcium reaching the blood from the GI tract (Tanaka et al., 1981). Calcium absorption into the bloodstream is an active process under control of a calciumbinding protein and in most species is vitamin-D dependent (Soares et al., 1995). It is a priority for all mammals to maintain calcium concentrations in plasma and extracellular fluids close to $10 \mathrm{mg} / \mathrm{dL}$ in the face of large fluctuation in demand and lesser fluctuations in supply (Hurwitz, 1996).

The calcium requirement varies throughout life. Most farm animals require diets that are between 0.5 and 1 percent calcium. Forages are generally satisfactory sources of calcium for grazing livestock, particularly when they contain leguminous 
species (Underwood and Suttle, 1999). Most grain-based concentrates are low in calcium and are insufficient unless supplemented.

There have been no rigorous attempts to define the calcium requirements of sheep or cattle by means of feeding trails and the requirement is determined by factorial estimates (Underwood and Suttle, 1999). It has been found that under grazing conditions, low calcium concentrations are seldom a problem with either Angora or meat-type goats, but dietary calcium concentration is very important for dairy goats because low calcium diets lead to reduced milk production (NRC, 2007).

\section{How Calcium Bioavailability is Measured}

Calcium is absorbed in the duodenum and jejunum of most animals (Pond et al. 2005). Absorption of a mineral element by an animal may provide an estimate of the bioavailability (Ammerman, 1995). Absorption studies of several days in length have been used most frequently with ruminant animals to assess bioavailability of macrominerals such as calcium, phosphorus and magnesium (Ammerman, 1995). The apparent absorption is determined by subtracting the total fecal excretion of a specific mineral from the amount of the mineral ingested. This is referred to as apparent absorption because it does not correct for the portion of the element present in feces that resulted from the excretion of the element into the gastrointestinal tract (Ammerman, 1995). True absorption corrects for the portion of the element which has been absorbed by the body and excreted back into the gastrointestinal tract but this method is limited to the elements calcium and phosphorus in ruminant animals (Ammerman, 1995). Net retention is determined 
as the total intake of a mineral minus the sum of the fecal and urine excretions of that mineral.

\section{Factors Effecting Calcium Absorption and Bioavailability}

Diet: Calcium bioavailability is greatly affected by the calcium to phosphorous ratio in the diet (Kim et al, 1985; Albanese et al., 1986; Lopes and Perry, 1986). Ruminants can tolerate relative high calcium to phosphorus ratios if magnesium is not high in the diet (Chester-Jones, et al. 1998). The concentration of calcium in the diet also affects the amount absorbed. Calcium absorption generally decreases as the calcium concentration in the diet increases (Pond et al., 2005).

Vitamin D plays an essential role in the absorption and metabolism of calcium and phosphorus (NRC, 2007). The absorption of calcium is both an active and passive process and in the active process it is mediated by vitamin D (Deluca, 1974; Norman, 1987). In swine, absorption of Ca is increased by vitamin D, decreased by high dietary fat, decreased by acid $\mathrm{pH}$ in the contents, and decreased by phytin-P.

Certain minerals can have an effect on the transport and bioavailability of calcium in the body. Gibbons et al., (1972) reported that calcium transport in the body is enhanced by carbohydrates and by low luminal concentrations of sodium. Furthermore, additions of lactose (Baker et al., 1967; Moser et al., 1977; Rayssiquier and Poncent, 1980), casein (Chrisp et al., 1989), anion to cation ratio (Lomba et al., 1978), or source of protein (Biola and Phillips, 1988) have all been reported to increase calcium absorption and retention (Soares, 1995) in ruminants and nonruminants. Oxalate, phytate, phosphate, and excessive sulfate reduce the 
concentration of ionic calcium in the body and reduce its uptake by animals (Harrison, 1959; Nelson, 1967; Nelson et al., 1968).

Sources: Grains and high-starch feedstuffs are low in calcium content and of low importance as a source of calcium. Calcium concentration is generally lower in plants than in mineral sources but legumes can serve as an importance source of calcium for herbivores (Martz et al., 1990). Calcium carbonate is commonly used as a supplemental calcium source because it is inexpensive and because of its buffering capacity. It has been found that calcium carbonate may have low bioavailability in ruminants due to its poor solubility unless finely ground (NRC, 2005). Feedstuffs with calcium bioavailability of $95 \%$ or more compared to calcium carbonate in both ruminant and nonruminants include aragonite, bone meal, calcium gluconate, dicalcium phosphate, ground oyster shell, calcium sulfate, nonfat dry milk, and tricalcium carbonate (Soares, 1995). When the availability of calcium from dried skim milk was rated at 100, Greger et al. (1987) estimated the availability of calcium carbonate at $102 \%$ in comparison. Other calcium sources commonly used are alfalfa hay, defluorinated phosphate, low fluorine rock phosphate, anhydrous calcium chloride, calcium citrate, and soybean meal and are considered to be 85 to $95 \%$ available (Soares, 1995).

Age and Species: It has been shown that younger animals retain more calcium than mature animals (Hansard et al., 1954, 1957; Harrison, 1959; Horst et al., 1978). When Hansard et al. (1957) compared growing heifers to mature cattle, it was observed that the greatest differences in calcium availability was due to animal age. In both sheep and cattle, the calcium requirement for growth decreased with 
age but increased with increasing growth rate. The Ca requirement for cattle is 4.5 $\mathrm{g} / \mathrm{kg} \mathrm{DM}$, which is $50 \%$ higher than the concentration for sheep (Underwood and Suttle, 1999). The recommended Ca concentrations in dog foods with 4 Kcal ME/g dry matter (DM) are $1.2 \%, 0.8 \%$, and $0.3 \%$ of DM for growth, late gestation/lactation, and adult maintenance respectively (NRC, 2004). The recommended Ca concentrations in cat foods with $4 \mathrm{Kcal} \mathrm{ME} / \mathrm{g}$ DM are $0.80 \%$, $1.08 \%$, and $029 \%$ of DM for growth, late gestation/lactation, and adult maintenance, respectively (NRC, 2004).

\section{Conclusion}

Calcium plays an essential role in the body. There are many forms of calcium that can be used as supplements when the diet is inadequate in calcium. However, while the appropriate calcium source to be included in a diet should be determined by its relative bioavailability, the choice of a calcium source may be made based on relative cost of the specific calcium source. The objective of this study was to determine the bioavailability of different calcium sources by determining calcium absorption and retention of these sources by goats. 


\section{Literature Cited}

Albanese, A. A., E. J. Lorenze, A. H. Edelson, A. Tarlow, E. H. Wein and L. Carroll. 1986. Effects of dietary calcium: phosphorus ratios on utilization of dietary calcium for bone synthesis in women 20-75 years. Nutr. Rep. Int. 33:879 - 891.

Ammerman, C. B., D. H. Baker and A. J. Lewis. 1995. Bioavailability of Nutrients for Animals. Academic Press, San Diego, CA.

Baker, D. H., D. E. Becker., A. H. Jensen and B. G. Harmon. 1967. Response of the weanling rat to alpha- or beta-lactose with or without an excess of dietary phosphorus. J. Dairy Sci. 50:1314 - 1318.

Biola, R. J. and G. D. Phillips. 1988. Effects of faunation, protein source and surgical modification of the intestinal tract upon flows of calcium, phosphorus, and magnesium in the digestive tract of sheep. Can. J. Anim. Sci. 68:853 - 863.

Chester-Jones, H., J. P. Fontenot and H. P. Veit. 1990. Physiological and pathological effects of feeding high levels of magnesium to steers. J. Anim. Sci. 68:4400 4412.

Chrisp, J. S., A. R. Skyes and N. D. Grace. 1989. Kinetic aspects of calcium metabolism in lactating sheep offered herbages with difference Ca concentrations and the effect of protein supplementation. Br. J. Nutr. 61:45 - 54 .

DeLuca, H. F. 1974. Vitamin D: The vitamin and the hormone. Fed Proc. 33:2211 2219.

Gibbons, R. A., B. F. Sansom, and R. Sellwood. 1972. The passage of calcium and strontium across the gut of the anaesthetized goat. J. Phys. 222:397 - 406. 
Greger, J. L., C. E. Krzykowski, R. R. Khazen and C. L. Krashoc. 1987. Mineral utilization by rats fed various commercially available calcium supplements or milk. J. Nutr. 117:717 - 724 .

Hansard, S. L., C. L. Comar and M. P. Plumlee. 1954. The effects of age upon calcium utilization and maintenance requirements in the bovine. J. Anim. Sci. 13:25 36.

Hansard, S. L., H. M. Crowder and W. A. Lyke. 1957. The biological availability of calcium feeds for cattle. J. Anim. Sci. 16:437 - 443.

Harrison, H. E. 1959. Factors influencing calcium absorption. Fed. Proc. 18:1085 1092.

Horst, R. L., H. F. DeLuca and N. A. Jorgensen. 1978. The effect of age on calcium absorption and accumulation of 1,25-dihydroxyvitamin $\mathrm{D}_{3}$ in intestinal mucosa of rats. Metab. Bone Dis. Relat. Res. 1:29 - 33.

Hurwitz, S. 1996. Homeostatic control of plasma calcium concentration. Cri. Rev. Biochem. Mol Biol. 31:41 - 100.

Kim, Y. S., S. S. Sun and K. H. Myung. 1985. The effects of level and method of calcium input, age, and particle size on true available calcium value in breeding Japanese quail. Korean J. Anim. Sci. 27:386 - 390.

Lopes, H. O. S. and T. W. Perry. 1986. Effect of dietary phosphorus and roughage levels on calcium, magnesium and potassium utilization by sheep. J. Anim. Sci. 63:1983 - 1989. 
Martz, F. A., A. T. Belo, M. F. Weiss and R. L. Belyea. 1990. True absorption of calcium and phosphorus from alfalfa and corn silage when fed to lactating cows. J. Dairy Sci. 73:1288 - 1295.

Moser, R. L., E. R. Peo, Jr., T. D. Creshaw and P. J. Cunningham. 1977. Effect of dietary lactose on gain, feed conversion, blood, bone and intestinal parameters in postweaning rats and swine. J. Anim. Sci. 51:89 - 99.

National Research Council. 2004. Nutrient Requirements for Dogs and Cats. National Academic Press, Washington, DC.

National Research Council. 2005. Mineral Tolerance of Domestic Animals. $2^{\text {nd }}$ Ed. National Academies Press, Washington, DC.

National Research Council. 2007. Nutrient Requirements of Small Ruminants: Sheep, Goats, Cervids, and New World Camelids. National Academies Press, Washington, DC.

Nelson, T. S., and T. R. Sheih. 1967. The utilization of phytate phosphorus by poultry - A review. Poult. Sci. 46:862 - 871.

Nelson, T. S., T. r. Shieh, R. J. Wodzinski and J. H. Ware. 1968. The availability of phytate phosphorus in soybean meal before and after treatment with a mold phytase. Poult. Sci. 47:1842 - 1848.

Norman, A. W. 1987. Studies on the vitamin D endocrine system in the avian. J. Nutr. 117:797 - 807 .

Pond, W. G., D. C. Church, K. R. Pond and P. A. Schoknecht. 2005. Basic Animal Nutrition and Feeding (5 $5^{\text {th }}$ Ed.). John Wiley \& Sons, Inc., Hoboken, NJ. pp. 165 $-171$. 
Rayssiquier, Y. and C. Poncet. 1980. Effect of lactose supplement on digestion of lucerne hay by sheep. II. Absorption of magnesium and calcium in the stomach. J. Anim. Sci 51:186 - 192.

Ross, R. D., G. L. Cromwell and T. S. Stahly. 1984. Effects of source and particle size on the biological availability of calcium in calcium supplements for growing pigs. J. Anim. Sci. 59: 125 - 134.

Soares, J. H. 1995. Calcium bioavailability. In: C. B. Ammerman, D. H. Baker, and A. J. Lewis (Ed.). Bioavailability of Nutrients for Animals. Amino Acids, Minerals, and Vitamins. Academic Press, Inc., San Diego, CA. pp. 95 - 118.

Underwood, E. J. and N. F. Suttle. 1999. The mineral nutrition of Livestock. $3^{\text {rd }}$ Ed. CABI Pulshining, Wallingford, Oxfordshire. 


\begin{abstract}
Calcium addition is necessary in order to balance the high phosphorus concentrations that are characteristic of high-concentrate ruminant diets. However, calcium sources differ in their bioavailability. Our objective was to determine apparent $\mathrm{Ca}$ and $\mathrm{Mg}$ absorption and retention in goats offered diets containing different sources of Ca. Spanish-Boer goats $(n=18 ; 19.6 \pm 1.88 \mathrm{~kg})$ were stratified by BW and sex and randomized to dietary treatments consisting of Purina Antlermax 16 containing either calcium carbonate (CC), Calmin (CM) or Milk Cal (MC). Goats were adapted to a control, corn-based high-concentrate diet on pasture and then moved to individual $1.0 \times 1.5 \mathrm{~m}$ pens with plastic coated expanded metal floors, and adjusted to their respective diets along with removal of hay from the diet over a 7-d period. Goats were then offered their respective diets at a total of $2 \%$ of BW in equal feedings at 0830 and $1700 \mathrm{~h}$ for an additional 14-d adaption period to diet and facilities followed by a 7-d collection of total urine and feces. Data were analyzed using PROC MIXED of SAS. Calcium and Mg intake were not different $(P \geq 0.12)$ among diets. Calcium and Mg apparent absorption and retention $(\mathrm{g} / \mathrm{d}$ and $\%$ of intake) were greatest $(P<0.05)$ in goats offered $\mathrm{CC}$ and did not differ $(P \geq 0.20)$ between goats offered the CM and MC diets. Therefore, calcium and magnesium were more available for goats from the diet containing calcium carbonate compared with diets containing Calmin and Milk Cal.
\end{abstract}




\section{Introduction}

Calcium is essential for growth and maintenance of bones and teeth and is the most abundant mineral in the body (Soares, 1995). Ninety-nine percent of the body's calcium is located in the skeleton and the remaining $1 \%$ is crucial for cellular metabolism, blood clotting, enzyme activation, and neuromuscular action (Soares, 1995). Calcium bioavailability is greatly affected by the calcium-to-phosphorous ratio in the diet (Kim et al, 1985; Albanese et al., 1986; Lopes and Perry, 1986). In high concentrate diets, calcium addition is required to balance the high levels of phosphorus in the diet. The optimal calcium-to-phosphorus ratio is $2: 1$ but ruminants can tolerate relative high calcium-to-phosphorus ratios if magnesium is not high in the diet (Chester-Jones et al., 1990). Calcium carbonate is commonly used as a supplemental calcium source because it is inexpensive and because of its buffering capacity. When the availability of calcium from dried skim milk was rated at 100, Greger et al. (1987) estimated the availability of calcium carbonate at 102\% in comparison. Other sources of calcium are available that have potential value as supplements for which little information is available. Therefore, the objective of this study was to determine the bioavailability of calcium and magnesium in growing goats offered different calcium sources.

\section{Methods and Materials}

The University of Arkansas Animal Care and Use Committee approved all procedures (IACUC \#15062). Spanish $\times$ Boer crossbred goats $(\mathrm{n}=18 ; 19.6 \pm 1.88 \mathrm{~kg})$ 
were purchased from a single source, vaccinated against 8 clostridial strains (Covexin 8; Merck Animal Health, Intervet, Inc., Madison, NJ), dewormed with levamisole hydrochloride (Prohibit Soluble Drench Power Anthelmintic, Agri Laboratories, Ltd., St. Joseph, MO), and co-mingled on a predominantly bermudagrass (Cynodon dactylon L.) pasture. During this time, goats were offered increasing amounts of a control, corn-based high-concentrate diet on the pasture until they were consuming the diet at $2 \%$ of BW. They were then stratified by BW and sex and allocated randomly to dietary treatments consisting of a commerciallyavailable pelleted $\operatorname{diet}^{1}$ containing either calcium carbonate (CC), Calmin (CM) or Milk Cal (MC). Calmin is sourced from red algae off of the coasts of Ireland and Iceland. Milk Cal is calcium sourced from milk. Diets were formulated to contain $16 \%$ crude protein $(\mathrm{CP}), 0.6 \%$ calcium, $0.48 \%$ phosphorus, $0.5 \%$ magnesium and $1.4 \%$ potassium. Goats were moved to individual $1.0 \times 1.5$-m pens with plasticcoated expanded metal floors located in an insulated metal barn with exhaust ventilation and adjusted to their respective diets along with removal of hay from the diet over a 7-d period. Goats were then offered their respective diets at 0830 and 1700h for an additional 14-d adaption period to diet and facilities followed by a 7-d collection of total urine, feces and orts. Orts and fecal samples were collected at $0830 \mathrm{~h}$ daily, weighed, and dried to a constant weight at $50^{\circ} \mathrm{C}$ in brown paper bags. Total urine for each goat was collected daily at $0800 \mathrm{~h}$, weighed, mixed thoroughly, and a $10 \%$ aliquot by volume was placed in individual plastic containers and stored frozen $\left(-20^{\circ} \mathrm{C}\right)$. Urine samples were composited across days within goat. Forty $\mathrm{mL}$ of

\footnotetext{
${ }^{1}$ Purina Antlermax 16, Purina Animal Nutrition, LLC, Gray's Summit, MO.
} 
HCL ( $50 \% \mathrm{v} / \mathrm{v})$ were added prior to each daily urine collection to prevent ammonia volatilization by microbial action. Representative samples of feed were taken daily as feed was weighed for the goats and dried to a constant weight at $50^{\circ} \mathrm{C}$ in brown paper bags. After drying, feed and fecal samples were allowed to equilibrate to atmospheric moisture in a temperature-controlled room $\left(20^{\circ} \mathrm{C}\right)$ and ground to pass a 1-mm screen in a Wiley mill (Author H. Thomas, Philadelphia, PA).

Concentrations of calcium and magnesium were determined using Inductively Coupled Plasma Emission Spectroscopy after wet ashing with concentrated trace mineral grade nitric acid (ICP-OES; Method 985.01; AOAC, 2000). All laboratory analyses were corrected to a DM basis (Method 934.01; AOAC, 2000).

Data were analyzed using PROC MIXED of SAS with animal considered the experimental unit and treatment as the fixed effect. Sex and the sex $\times$ treatment interaction were included in the original model but the interaction was not significant $(P \geq 0.63)$ for any of the variables measured. Therefore, these effects were removed from the final model. One goat on the $\mathrm{CC}$ diet and one goat on the MC diet did not consume their diets and their data were therefore excluded from the data analyses. Treatment means were compared using an F-protected t test. All data are reported as least-squares means.

\section{Results and Discussion}

Calcium composition was slightly greater in CC in comparison to MC and CM (Table 1) with no difference in calcium composition between MC and CM. Magnesium and $\mathrm{K}$ composition was similar among the three diets. 
Dry matter intake $(\mathrm{g} / \mathrm{d})$ and apparent digestibility $(\%)$ did not differ $(P=$ 0.97 and 0.14 , respectively) among the three diets (Table 2). Calcium intake (g/d) did not differ $(P=0.12)$ among the three diets (Table 3). Calcium apparent absorption and retention $(\mathrm{g} / \mathrm{d}$ and $\%$ of Ca intake) were greatest $(P<0.05)$ from $\mathrm{CC}$, but did not differ $(P \geq 0.20)$ between $\mathrm{MC}$ and $\mathrm{CM}$.

Magnesium intake (g/d) did not differ $(P \geq 0.12)$ among the three diets (Table 4). Magnesium apparent absorption and retention ( $\mathrm{g} / \mathrm{d}$ and $\%$ of $\mathrm{Mg}$ intake) were greatest $(P<0.05)$ from $\mathrm{CC}$ and did not differ $(P \geq 0.69)$ between $\mathrm{CC}$ and $\mathrm{MC}$.

In this study we chose to compare the bioavailability of calcium carbonate, Calmin, and Milk Cal from the commercial pellet Antlermax 16. Antlermax 16 is a high-concentrate diet formulated to contain $16 \%$ crude protein and is intended as a complete diet for growing deer to help support antler growth. However, we used goats as the experimental model instead of deer, because goats have similar digestive tracts (Van Soest, 1994) and are easier to collect fecal and urine samples from within metabolism crates than deer. Knowing the absorption and retention of calcium from Calmin, Milk Cal and calcium carbonate is useful for determining the appropriate source and amount that should be added to the diet in order to maintain optimal horn growth and strength in deer.

Calcium source did not affect diet digestibility in the present study. Digestibility of cattle feedlot diets was not affected by substituting dolomitic limestone - a calcium source with demonstrated lower availability of $\mathrm{Ca}$ and $\mathrm{Mg}$ for calcium carbonate (Crawford et al., 2008). Growing pigs offered diets with calcium carbonate consumed more feed than those offered diets with a number of 
other calcium sources, but feed conversion efficiency was not affected by Ca source (Ross et al., 1984). In our study, diet intake was restricted, which also potentially limited differences in digestibility due to Ca source. Other data pertaining to the impacts of different sources of Ca on digestibility of high-concentrate diets for ruminants is limited.

The diets in this study were formulated to contain $0.6 \%$ calcium but the CC diet actually contained more calcium $(0.77 \%)$ compared with MC $(0.6 \%)$ and $\mathrm{CM}$ (0.59\%). Although not different statistically $(P=0.12)$, this differential Ca concentration along with offering all diets at $2 \%$ of BW resulted in goats that were offered CC actually consuming 0.61 and $0.58 \mathrm{~g} / \mathrm{d}$ more Ca than goats offered CM and MC, respectively. The Ca from the CC diet was the most bioavailable in comparison to $\mathrm{MC}$ and $\mathrm{CM}$. However, this was likely not a result of the numerical increase in Ca intake because the proportion of calcium absorbed from diets is generally inversely proportional to diet calcium concentrations (Pond et al., 2005).

In a summary across a number of mammal species, calcium carbonate had equivalent $\mathrm{Ca}$ absorption to a number of other Ca sources including nonfat dry milk and dried skim milk (Soares, 1995). Ross et al. (1984) reported that growing pigs fed diets with calcium carbonate consumed more feed compared with pigs fed diets with a number of other calcium sources but calcium source did not affect other measurements including femur strength and relative calcium bioavailability. Human subjects showed no effect of calcium carbonate versus milk on urinary calcium concentrations (Martini and Wood, 2002). Therefore, calcium carbonate appears to 
be comparable to other more expensive Ca sources in its value as a Ca source for small ruminants.

The only supplemental Mg source used in these diets was Mg oxide, which is considered the standard Mg source in livestock diets. Since Ca and Mg can potentially affect the absorption of each other (Pond et al., 2005), it was also necessary to determine the impacts of Ca source on Mg absorption. The CC diet had the greatest apparent absorption and retention of Mg compared with the diets with CM and MC. Therefore, calcium carbonate does not appear to have a negative impact on Mg bioavailability compared with other supplemental Ca sources.

\section{Summary and Conclusion}

Calcium and magnesium were more available for goats consuming the diet containing calcium carbonate compared with the diets containing Calmin and Milk Cal. Calcium carbonate is also less expensive typically than the other sources evaluated in this study. Therefore, it is not necessary to include these more expensive sources in order to improve calcium and magnesium bioavailability.

\section{Acknowledgments}

I would like to thank the Purina Animal Nutrition Center for providing the feed along with funding the laboratory analyses and labor for this study. 


\section{Literature Cited}

Albanese, A. A., E. J. Lorenze, A. H. Edelson, A. Tarlow, E. H. Wein and L. Carroll. 1986. Effects of dietary calcium: phosphorus ratios on utilization of dietary calcium for bone synthesis in women 20-75 years. Nutr. Rep. Int. 33:879 - 891.

AOAC. 2000. Official methods of analysis of the Association of Official Analytical Chemists International (17th Ed.) Gaithersburg, MD.

Chester-Jones, H., J. P. Fontenot and H. P. Veit. 1990. Physiological and pathological effects of feeding high levels of magnesium to steers. J. Anim. Sci. 68:4400 4412.

Crawford, G. I., C. D. Keeler, J. J. Wagner, C. R. Krehbiel, G. E. Erickson, M. B. Crombie and G. A Nunnery. 2008. Effects of calcium magnesium carbonate and roughage level on feedlot performance, ruminal metabolism, and site and extend of digestion in steers fed high-grain diets. J. Anim. Sci. 86:2998 - 3013.

Greger, J. L., C. E. Krzykowski, R. R. Khazen and C. L. Krashoc. 1987. Mineral utilization by rats fed various commercially available calcium supplements or milk. J. Nutr. 117:717 - 724 .

Kim, Y. S., S. S. Sun and K. H. Myung. 1985. The effects of level and method of calcium input, age, and particle size on true available calcium value in breeding Japanese quail. Korean J. Anim. Sci. 27:386 - 390.

Lopes, H. O. S. and T. W. Perry. 1986. Effect of dietary phosphorus and roughage levels on calcium, magnesium and potassium utilization by sheep. J. Anim. Sci. 63:1983 - 1989. 
Martini, L. and R. J. Wood. 2002. Relative bioavailability of calcium-rich dietary sources in the elderly. Am. J. Clin. Nutr. 76:1345 - 1350.

Pond, W. G., D. C. Church, K. R. Pond and P. A. Schoknecht. 2005. Basic Animal Nutrition and Feeding (5 ${ }^{\text {th }}$ Ed.). John Wiley \& Sons, Inc., Hoboken, NJ. pp. 165 $-171$.

Ross, R. D., G. L. Cromwell and T. S. Stahly. 1984. Effects of source and particle size on the biological availability of calcium in calcium supplements for growing pigs. J. Anim. Sci. 59: 125 - 134.

Soares, J. H. 1995. Calcium bioavailability. In: C. B. Ammerman, D. H. Baker, and A. J. Lewis (Ed.). Bioavailability of Nutrients for Animals. Amino Acids, Minerals, and Vitamins. Academic Press, Inc., San Diego, CA. pp. 95 - 118.

Van Soest, P. J. 1994. Nutritional Ecology of the Ruminant. (2nd Ed.). Cornell Univ. Press. Ithaca, NY. 
Table 1. Calcium and magnesium composition of Antlermax 16 diets with different calcium sources that were offered to growing goats.

\begin{tabular}{|lccc|}
\hline & & Diets $^{1}$ & \\
\cline { 2 - 4 } Composition & Calcium Carbonate & Calmin & Milk Cal \\
\hline Calcium, \% & 0.77 & 0.59 & 0.60 \\
Magnesium, \% & 0.50 & 0.46 & 0.46 \\
Potassium, \% & 1.36 & 1.36 & 1.43 \\
\hline
\end{tabular}

${ }^{1}$ Calmin is calcium extracted from red algae; milk calcium is calcium extracted from milk. 
Table 2. Dry matter intake and digestibility by growing goats offered Antlermax 16 with different calcium sources.

\begin{tabular}{|c|c|c|c|c|}
\hline \multirow[b]{2}{*}{ Item } & \multicolumn{3}{|c|}{ Diets $^{1}$} & \multirow[b]{2}{*}{ SEM } \\
\hline & $\begin{array}{c}\text { Calcium } \\
\text { Carbonate }\end{array}$ & Calmin & Milk Cal & \\
\hline DM intake, g/d & 368 & 372 & 372 & 1.87 \\
\hline DM digestibility, \% & 75.5 & 72.2 & 729 & 32.97 \\
\hline
\end{tabular}

${ }^{1}$ Calmin is calcium extracted from red algae; milk calcium is calcium extracted from milk. 
Table 3. Calcium balance by goats offered Antlermax 16 with different sources of supplemental Ca.

\begin{tabular}{|c|c|c|c|c|}
\hline \multirow[b]{2}{*}{ Item } & \multicolumn{3}{|c|}{ Diets $^{1}$} & \multirow[b]{2}{*}{ SEM } \\
\hline & $\begin{array}{c}\text { Calcium } \\
\text { Carbonate }\end{array}$ & Calmin & Milk Cal & \\
\hline Intake, g/d & 2.82 & 2.21 & 2.24 & 0.878 \\
\hline Apparent absorption, $\mathrm{g} / \mathrm{d}$ & $0.97^{a}$ & $0.27^{b}$ & $0.22^{b}$ & 0.170 \\
\hline Apparent absorption, \% & $32.4^{a}$ & $11.6^{b}$ & $10.1^{b}$ & 5.71 \\
\hline Retained, g/d & $0.91^{a}$ & $0.24^{b}$ & $0.18^{b}$ & 0.172 \\
\hline Retained, \% of intake & $30.1^{a}$ & $10.1^{b}$ & $8.1^{\mathrm{b}}$ & 5.85 \\
\hline Retained, mg/kg BW & $43.7^{a}$ & $11.4^{b}$ & $9.2^{\mathrm{b}}$ & 7.11 \\
\hline
\end{tabular}

a,b Means within a row without a common superscript letter differ $(P<0.05)$

${ }^{1}$ Calmin is calcium extracted from red algae; milk calcium is calcium extracted from milk. 
Table 4. Magnesium balance by goats offered Antlermax 16 with different sources of supplemental Ca.

\begin{tabular}{|lcccc|}
\hline & \multicolumn{3}{c|}{ Diets $^{\mathbf{1}}$} & SEM \\
\cline { 2 - 4 } Item & $\begin{array}{c}\text { Calcium } \\
\text { Carbonate }\end{array}$ & Calmin & Milk Cal & \\
\hline Intake, g/d & 1.85 & 1.71 & 1.71 & 0.155 \\
Apparent absorption, g/d & $0.93^{\mathrm{a}}$ & $0.52^{\mathrm{b}}$ & $0.48^{\mathrm{b}}$ & 0.088 \\
Apparent absorption, \% & $49.2^{\mathrm{a}}$ & $31.1^{\mathrm{b}}$ & $29.9^{\mathrm{b}}$ & 4.00 \\
Urine Mg, g/d & $0.47^{\mathrm{b}}$ & 0.47 & 0.41 & 0.058 \\
Retained, g/d & $0.46^{\mathrm{a}}$ & $0.05^{\mathrm{b}}$ & $0.08^{\mathrm{b}}$ & 0.073 \\
Retained, \% of intake & $24.1^{\mathrm{a}}$ & $2.9^{\mathrm{b}}$ & $5.2^{\mathrm{b}}$ & 4.12 \\
Retained, mg/kg BW & $23.1^{\mathrm{a}}$ & $2.5^{\mathrm{b}}$ & $4^{\mathrm{b}}$ & $3.5^{\mathrm{b}}$ \\
\hline
\end{tabular}

a,b Means within a row without a common superscript letter differ $(P<0.05)$

${ }^{1}$ Calmin is calcium extracted from red algae; milk calcium is calcium extracted from milk. 